\title{
The Nature of Ismail Zain's Art: A Different Vision in Malaysian Contemporary Art
}

\author{
Issarezal Bin Ismail \& Setiawan Sabana \\ Faculty of Art and Design, Bandung Institute of Technology (ITB) - INDONESIA
}

\begin{abstract}
This study is an exploration of Ismail Zain's art, one of the pioneers in new media art in Malaysia. It will focus on his outstanding display in Digital Collage exhibition, an exhibition was notable by art critics from Malaysia and Asia Pacific as the touchstones of a new approach in art which was a nonpersonalized medium that specifically depended on highly mechanized consideration. The purpose of this study is to explore Ismail's art in terms of the process itself. In order to understand the nature Ismail's art, there are three important questions: What are the idea and concept in his art? What are the medium and technique that were used in his art? How was the artwork itself? These questions are addressed by data gathered in Malaysia through collection of the artifacts, documents regarding interviews, and some institutional historical resources. The data have been divided and presented into the following themes: (a) conception, (b) operations and (c) synthesis.
\end{abstract}

Keywords: digital collage exhibition; ismail zain; Malaysian contemporary art.

\section{$1 \quad$ Introduction}

In the year of 1988, Malaysia's art scene was shocked by a one-man show titled Digital Collage by Ismail Zain who at that time was at the age of 53. Walking through this particular exhibition, you could hear derisive comments reflecting deep suspicion of the changes that had been made in Malaysian contemporary art. Exhibited in Balai Seni Lukis Negara, one of the most prestigious and prominent galleries in the heart of Malaysia, this exhibition was notable by art critics from Malaysia and Asia Pacific as the touchstones of a new approach in art which was a non-personalized medium that specifically depended on highly mechanized consideration.

For those who wished the visual art to address con-temporary concerns, such developments were a source of deep anxiety. After so many years of dominance from abstract art tendencies, especially in relation to a Malay-Islamic centered art since its independence, traditional forms and media such as painting and sculpture had increasingly been abandoned by artists in favors of multidisciplinary, mixed-media installations and now been radically transformed in confront ways and form called new media art [1]. In spite of research spawned by increasing number of the history of Malaysian 
contemporary art, very little has been written about positioning Ismail Zain in their context of studies although the compliment for this exhibition nor the artist were always highly rated.

Besides one retrospective writings that was supplemented in the posthumous exhibition titled Ismail Zain: Retrospective Exhibition 1964-1991 (1995), four years after of his demise at 56 years old, there is not much details in other writings regarding this magnificent creative individual and work of art. For example, Redza Piyadasa when examined the historical of Modern Malaysian Art from 1945-1991 (1993) stated only a couple of lines regarding Ismail Zain's contribution in Malaysia art scene [1].

It also much or less the same case with Antoinette [2] who critically observed a development of Malaysian contemporary art since 1990s. She only mentioned Ismail Zain in one sentence. But, it offers enough information about the paramount importance of Ismail Zain in Malaysian contemporary art gener-ally and in new media art specifically. According to Antoinette [2], the importance of new media art was heralded in a major solo show called the Digital Collage Exhibition in 1988, which featured the work of Ismail Zain.

Ironically, this exhibition was his first solo exhibition and the only exhibition in his life that was two years before his retirement as a government servant. From this point of departure, this writings can be considered as one little piece of information that is dedicated to look back at this pioneer artist's not in the context of life histories but to this particular exhibition.

\section{Methodology}

Design of this study is based on the qualitative tradition point of view based on its descriptive and exploratory quality. All the data from this study comes from observation, visual recording, and documentation. From this interaction, data are generated, coded, and analyzed in order to find pattern, relationship, and idiosyncratic ideas and values. The data consisted of my impression, the artifacts that have been scanned or photocopied, historical and procedural document and literature about topic considered relevant to this topic area. In order to analyzed, this study will take only a couple of exhibits from the show. From the descriptive and interpretative view, these criticisms activities try to break down all three factors lies in the art of Ismail's and freely mix comments on his conception, operation and synthesis, and draw upon both internal information and external information. The findings have been assembled into Malaysian contemporary art history about specific individual which is selected purposely in this context of studies. 
Any definition of art, by the very nature of it's subject, incomplete and open to dispute. Read [3] suggests that art has been so elusive, is explained by the fact that it has always been treated as a meta-physical concept, whereas it is fundamentally an organic and measureable phenomenon. Like breathing it has rhythmic elements; like speech expressive elements; but 'like' does not in the case express an analogy; art is deeply involved in the actual process of perception, thought and bodily action. It is not so much a governing principle to be applied to life as a mechanism which can be ignored at our peril.

Art, like other form of knowledge, has its own structure of concept, procedures and criteria. It is through an understanding of these art can be comprehended as a whole, but there can be no finite understanding of art for at any level, the concepts, the procedures and criteria are the focus of speculation not the object of ultimate mastery [4]. To under-stand the nature of art, this study will use concept offered by Barret. In his view, art can be studied in terms of the overall process. That's mean art is a combination of integral parts which is can be related to knowledge, skill, set of rules, process, and form it-self. The sum of all our visual knowledge is not only what we know, but the way we know it and respond to it. It is the commitment to this idea which forms the crucial concern in art.

It is something which can be recognized only entirely or in its unity, but which can be defined only by describing its main facets (Figure 1).

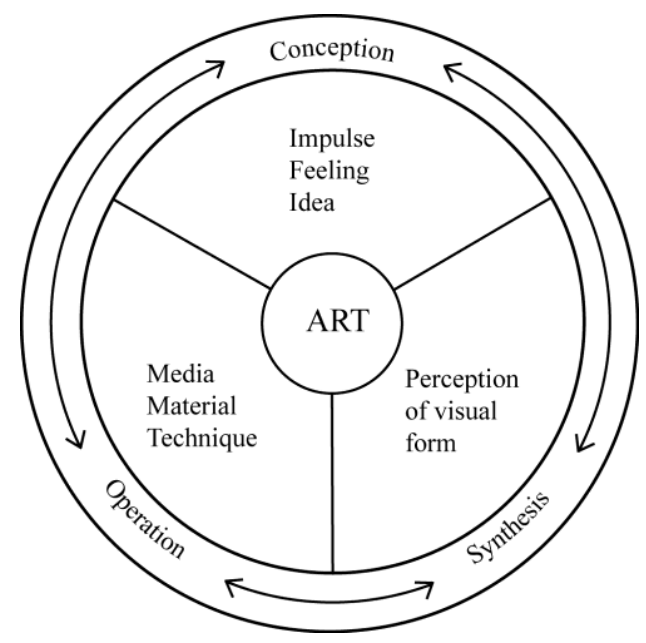

Figure 1 The Nature of Art.

The three facets in the conceptual framework offered by Barret, are dealt with as if they were separate entities, unless the elements are reflexive. In other 
words, the parts are inter-related so that each responds to explain, or change the others. The conceptual element consists of idea, impulse, and feelings. This is the aspect of art concerned with personal reality, concept formation, response to sensation and experience, and the realization of phenomena, symbols, myth, and fantasies. It operates through sensation, emotion, reminiscence, association, and interference.

The operational element consists of media, material, technique. This is the aspect of art concerned with physical nature of the world and the ways of using it as a means of developing and understanding it. It is through the manipulation of the environment that we are able to control it for our personal or social ends. The materials are everything that we use. They be-come the media through which we express and communicate our ideas, impulse, feelings. The effective use of these materials is achieved through the development of the appropriate technique and skills so that our results match our concepts.

The last facet is the dynamics of visual forms. It belongs to structure of visual form which is used to convey the concept through the materials. Perception is the basis for this element and involves the unified apprehension of the external world. The form of art is the shape that it takes. So, by this explanation, art in this concept can be summarized as the use of media to organize our subjective experience in visual forms.

\section{Context}

Generally, context of this study is Malaysian contemporary art. Contemporary art world seems to exist in a zone of freedom, set apart from the mundane character of its rules and conventions. In that zone of freedom, alongside with quieter contemplation and intellectual play, there flourished a strange mix of carnival and novelty, bilious transgressions in attitude, and offences against the fixed system in art.

Apart from these issues of freedom, it has also been an issue that artistic practice itself has made prominent, for new artistic movement that always challenge traditional understandings on art in such way that the status of their products as art has been questioned. Since that, the artwork displayed in museum or galleries may start to open their space to current mode of artistic forms beside faintest resemblance dedicated to the art of earlier ages. Although most of us may not be as ready to jettison our friend or families for the sake of our artistic allegiances, we share the same deep perplexities about contemporary works of art. 
Underlying many of these new or revised art forms has been a drive towards conceptual art-making approaches, which seek to disrupt established ideologies and cultural norms, often in provocative and confronting ways. The conceptualmaking approach in Malaysian contemporary art was started during the 70s after a few lucky young artists were given the art scholarship to attain higher education in art in the United Kingdom or United States of America. After returning to Malaysia, the engagement in study art proper changed their perspective and approach, then signaling shifts towards cultivating conscious, reflective methods of creativity, as well as expanding art studies into approximating field of knowledge.

With a conceptual art spirit, they started to promulgate ideas and concept which were aimed to challenge, or even undermine, prevailing aesthetic values in Malaysian art at that time. Such declaration established new framework within which particular artists could accommodate their individual concept and lo-cate their respective productions. Further, the freedom of expression allowed in the visual arts and the easy exposure to contemporary international frame of reference have resulted in development peculiar to the Malaysian context. Perhaps this is not unusual in what they called Third World countries where an autonomous intellectual tradition is still relatively new and the supportive dialectical relation to society has yet to be properly constituted.

According to Antoinette [2], Malaysian contemporary art since late 1980s was marked deeply by a heightened awareness of various global process, including developments in the sphere of international art. Globally linked economic and technological transformation in Malaysia has resulted in profound changes, including the emergence of new modes of production. Significantly, the cultural dynamics of globalization have made Malaysia more susceptible to global flows of mass and popular culture.

\section{$4 \quad$ Data}

\subsection{Conception}

Art is founded on the belief that sensory experience is the best way of knowing, thinking and feeling. This is concerned with the relationship between our inner reality and our sensory experience of the environment, together with any outcomes of this relationship. It is also the best means of receiving, organizing, understanding, and transmitting our own impulses, feelings, and ideas.

\subsubsection{Impulse and Feeling}

From the interview (1999), Ismail had confirmed his inner-feeling lucidly as quoted in the following: "My desire is that we have to understand the roles of 
art today, especially with the pre-eminence of instant in-formation and electric circuitry, and more so if we think that the so-called modern art is already lounging on a comfortable deck chair, we must look beyond the traditional concept of historicism".

From this statement, it clearly shows the artist's feeling about the urgency to repositioning art roles into and open concept. When he suggested that Malaysian art must look beyond the traditional concept of historicism is what he intended to say was in the aesthetics sense. In aesthetics theory, in the sense of a true definition or set of necessary and sufficient properties of art has been debated through ages.

According to Weitz [5], each age, each art movement, each philosophy of art tries over and over again to establish the stated ideal only to be succeeded by a new or revised theory, rooted, at least in part, in the repudiation of proceeding ones. So, the concept of art offered by traditional historicism if we take into consideration is played through definitional one. Therefore, by the open concept, artist does not come into the definable ways in thinking about art, rather focuses on its roles and its contribution primarily in order to show that it is of the greatness importance to our understanding of the art itself.

By not defining art through its set of properties, new condition will undoubtedly constantly arise, new art forms, new movement will emerge. Openness in art will lead to breaking the boundaries and allowing interaction between art and social-cultural condition. In Ismail's context, open-endedness in understanding art has led the artist to a new, overlapping, pluralistic tendency in relation to electronic age where realities of the world that have been agreed are challenged by the emergence of new technologies.

Moreover, Ismail (1999) added: "In my view, I want to think of it (art) more in textual model - already been written, allegorical and contingent, in which master narrative are challenge with the discourse of others. I also don't have to define what I do in relation to given medium but rather in relation to the logical operations on a set of cultural terms."

Ismail's interest and desire of textual approach generally can be described as conceptual art. Since 1960s, language has become important to many artist as the brushstroke has remained to others. In this decade, language entered the visual arts not as a sup-porting discourse supplied by critics for a formalist art but rather was manipulated, investigated, and controlled by artists themselves. Art and aesthetics were linked and discourse in art becomes part of art itself. 
It was Conceptualism, which was integrating theory and language in art. According to Prinz [6], when Henry Flint defined concept art in the Fluxus book: An Anthology, he described the artistic activity that would dominate the decade. Literally, concept art is an art of which material is concept. Since concept is close bound to language, concept art is a kind of art of which the material is language. The idea of the artistic product or process becomes art, whether or not the artist or viewer chooses to enact the activity described. Art thus changes its focus from the form of the language to what is being said, meaning that it changes the nature of art from the question of morphology to a question of function. This changes one from appearance to conception, and that is the beginning of conceptual art.

Indeed, while many artists in the 1960s and 1970s turned to text and photography as rational means a critiquing traditional aesthetics, others began to question the neutrality of such traditional media. In the age of world saturated by commercially generated imagery, like advertising, in which pictures and words are deployed in order to persuaded, or even to deceive, by many artists in the 1980s, late 20th century conceptual art was considered to be little more than the citation of a tradition - an image of an image or a picture or a picture, or according to the influential French philosopher Jean Baudrillard, a simulation. The central of the spirit in the 1980s was appropriation art. According to Owens [7], appropriation art lies in the images that occur in the artist's work who generate images through the reproduction. The appropriation images may be a film still, a photograph, a computer drawing; it is often itself already a reproduction. However, the manipulations to which these images work to empty then to their resonance, their significance, their authoritative claim of meaning.

According to Joselit [8], appropriation art entails at least two types of qualities lie behind it; first, it decontextualizes images from their original contexts and association, but second, it causes advertisement or reproduction to be encountered as a work of art, drawing their attention to their form. Advertisement or TV's commercials through their seductive surface as through their explicit message, and a great deal of photograph or computer manipulation in the 1980s sought to derive a new language of surface from the bombardment of imageries.

In visual art, executing works which transform our experience of art from a conceptual art encounter are always identified by theoreticians as a shift. Accord-ing to Owens [7], the first ejecting is concerning a shift from nature to culture. It is also the same with Ismail when he made an important claim that his real interests were not in nature but in culture, thereby in-forming us the he was involved in a value-free investigation of "culture" and its operative constructs, namely, the way in which particularized symbols and signs are 
culture bound and are responsible for the way in which mythic values and perception are perpetuated.

His interests were, as such, clearly of an ontological nature and had to do with codified meaning and their uses. In Ismail's textual approach, he stated that allegory was his weapons to challenge meta-narrative. According to Owens [7], allegory first emerged in response to a similar sense of estrangement from tradition. In allegorical structure, then, one text is read through another, however fragmentary, intermittent or chaotic their relationship may be. Conceived in this way, allegory becomes the model of all commentary, all critique, in so far as these involved in rewriting a primary text in terms of its figural meaning.

\subsubsection{Idea}

The most important point of his idea in making art is based on culture, not just for this particular exhibition, but for Ismail's, it has always been culture. Anybody can go back and look at his work since the sixties, and you may find any example of self-indulgence, at least not in the manner of expressionist mode as a basis of his art. In his view, the under-standing of culture is not so much in anthropological sense, but in ontological sense, created not by men in their historical contingencies, but by man in his very being. But in this particular exhibition, Ismail's concerns were based on the effect of culture when information technology enters our everyday life. His own thinking was geared towards a new reconsideration of the efficacy of this media and popular culture medium in the present age of rapid information transfer procedures, shaped by the new paradigms underlying information technologies.

According to Jit [9], his close involvement with the film and television industries now had heightened his earlier interest in the idea linked with the phenomenon of the mass media context. His new interest and involvement with the computer then need to be viewed as a logical outcome of the new situation in which he had found himself. There were genuine need to find new approach that could satisfy his complex perceptions and realization.

One of his main ideas is about the realities in shrinking global village. Influenced by McLuhan, he stated (1999): "I think if you skip the close system of the modernism of the myth progress and desperately what to extricate yourself from the rarefied air of the so-called modernism, you are left with the situation which can only be described as spatial. It is space that does not locate you in a particular time-frame". 
What he was thinking is that the need for reconstruct understanding in the new context of the world where space and distance is begins to been divorce from our social-cultural life. In electronic era, that the rapid of development of new technologies altered the conventional notions of human perspective and conceptualization. Giddens [10] already makes the distinction between place and space and argue that in the conditions of latter. Place is best conceptualized by means of the idea of locale, which refer to physical settings of social activity as situated geographically. Place is understood in terms of conditions of copresence, namely the way social interaction and relation occur face to face in physically close environment. Appreciation of art for example, can only take place with physically close to the place of museum as what Ismail's tries to show in his art. By contrast, information technology system allow for social interaction to be conducted at a distance by their physical absence. For example, the space of appreciation art can be divorce from it's original context, from copresence in the gallery or museum to a screen in computer by great physical distance. For Giddens, this process is called disembedding mechanism. This is to say that the stretching of this social interaction across distance allows for the reconstruction of both time and space. New form of time and space can be constructed across territorial distance.

It can be understood that radical transformation in information technology will causing a new type of problems in modern aesthetic senses which is the dematerialized of the original, and a tireless duplication or simulacra of images. In Ismail's context, the status of the original is no longer can be defensible when information technology interfere contemporary art world. This age were marked as ages were a spirit who got a new rational, new language and its own new logic. This notion was a great challenge to modern aesthetics of authenticity since mechanical reproduction was invented. When Benjamin[11] suggests that an artwork is basically can be reproduce because such technology allows to do that, reproduction technology at that time still in such level of mechanical reproduction. But, in contemporary conditions, mechanical technology is overlap by this new technology that been accelerate by electronic devices.

Another aspect of his interest was lies on the bombardment of images in mass media. In the interview (1999), he said: "With new technologies, there is now new rational, a new logic, a new language. Take some of today's computerized music videos, where there is bombardment of both images and sound".

From his view, it is clear that the bombardment of images and sounds only can be transmitted through the manipulation of mass media when there are no longer boundaries and barriers. As world become smaller, we find ourselves plugged in and more aspects of our lives that have been flooded with cultural 
flows. As Appadurai [12] suggests, people, machinery, images, and ideas now flow increasingly in non-isomorphic path. In this sense, the sheer speed, scale, and volume of each of these flows are now so great that the disjuncture have become central to the politics of global culture.

If we take for an example of the flow of iconic images of entertainment business, then this iconic images are distributed through particular media form and such distribution is possible because through the prior distribution of particular communication technologies, such as television, radio, or the printing press. These images, then, received and discussed by particular people in particular contexts. The images travel, but they travel by different speeds, through different territories and space, and through different practices by different temporalities.

His interests in allegorical impulse, conceptual art, cultural orientation and bombardment of images caused by information technology was translated in a very witty and teasing style in the title of his solo exhibition, which was Digital Collage. When asked by Noordin Hassan (1999) what he meant by digital collage as a concept, he replied: "It's a very difficult word to use because it is already so well entranced. But, I needed a word to describe the juxtaposition of the iconic images, which by most account is what I do."

Juxtaposition has always been used as a concept of compelling a part-by-part, image-by-image reading that is temporal in character although the combination may be fragmentary and erect an impenetrable barrier to its course. In visual sense, juxtaposition is a concept to deny the possibility of precisely such links of connection which hinge on the readability of the inscription. It is full of ambiguity; they might, in fact, serve as emblems of that blind confrontation of antithetical meaning which characterizes the allegory impulse.

According to Owens [7], allegorical impulse can be identified as a shift from history to discourse. In juxtaposition mode, the shift from history to discourse first comes up with the reorientation of the conventional picture field from a horizontal to a flatbed. It allows artist to compile, combine, and juxtapose part by part and image by image that is temporal in character. At last, all attempts to decipher juxtaposition images that initially impel reading is al-so what block it. This is what an analogy made by Ismail regarding juxtaposition in Malay traditional practice, when he said: "The practice is pretty ancient. The Malay traditional poem, for example is a very good example of this especially if you look at the first two lines of the quatrain. The juxtaposition of unrelated objects or imageries which echo with nuance and promises, sometimes capriciously, in these two lines is the kind of thing I mean. It's how borrowed fragments of the signified can be summarized in one form or other many characteristics." 
According to Krauss [7], the only metaphor that suggests juxtaposition in art is that the picture plane itself is a dumping ground. She describes Rauschenbreg's Allegory, a combine painting executed in 1959 by analogize it to the human mind; Rauschenberg's works thus become allegories of consciousness or, perhaps, the unconsciousness. This is all the same for what Ismail referred to of his term collage. He said: "The term's derivative is not it as a technique, going back to Picasso, Kurt Schwitters and so on, but in what happens in our minds most of the time."

\subsection{Operation}

These are the means through which our feelings, ideas and concepts are transmitted and expressed. This does not mean that their roles are passive. They will interact with our inner reality through the senses. The range of possibilities is almost infinite in art be-cause information technologies for example, offers variety of media and techniques, which appear to present maximum opportunity for exploration and manipulation. According to Barrett [4], media, material and technique must be related to the whole art experience for them to play a significant function in art.

\subsubsection{Media and Material}

Since computers had been developed originally for solving scientific and engineering problems, it is not surprising that their use for producing digital sound and textual and visual imageries. As a result, artists may now come to the computer with their visual arts training intact, without the need to learn hard on programming.

All the artwork displayed in Ismail's exhibition were produced by using a computer, specifically named Macintosh SE HD SC (Figure 2) and the rest of the tool-kit that went with it which can be classified as a tool for office work. The Macintosh SE was a computer that had been built in the year 1987, a year before this very exhibition. Technically speaking, the biggest ability of Macintosh SE was that the hard drive was built inside the compact case, which was restyled to allow a fan and better ventilation and also had power to move the data fast within 0.25 megabytes per second. The SE used the same 9" b\&w screen and $8 \mathrm{MHz} 68000 \mathrm{CPU}$ as the earlier Macs, along with the same 800KB floppy drive.

In this sense, Ismail can be described as the visionary of Malaysian computer art. Although he had chosen to use this magnificent technology of human kind since 1984 in terms of artistic purposes, his full intention was only materialized two years before his retirement as a public servant in the age of 53 [13]. At that age, some artists can simply just sit comfortably with their square canvas and 
colors and avoid the complexity of computer language as a means of aesthetic pursuits. He had chosen to explore the full potential of the computer.

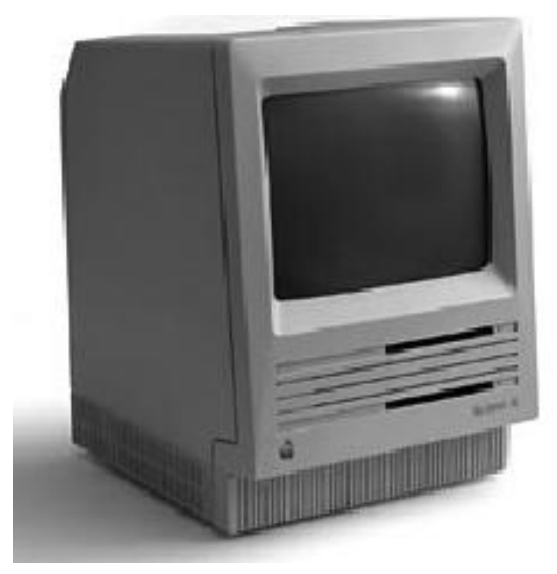

Figure 2 Macintosh SE HD SC.

When asked by Noordin Hassan (1999), why he chose computer as a tool for art, the artist replied: "Well, people should get less frightened of computer work of art. People always tend to think of computer as mechanical and that they lack human touch. This is misconception. This input is still done by humans. People are also frightened by programming. But with features such as Hypercard on the Mac, it allows the user to input applications into the system itself, without having to be a computer programmer. We need more people in this country before computer just seen as a hooked up for industrial purposes. For me, computer creates new dimension".

In this vast interweaving of conversation, a glimpse of new passage has been created. This by all means that cultural transformation that brings up media technology such as computer can be seen as broaden in scope, to the extend that technology can be integral with art and it is possible to represent or experience the process of making art through this mediation. With computers, there is now a new rational, a new logic, a new language. So, by dealing with such a technology, it allows artist to conceptualize things differently and not to be stuck in conventional status.

\subsubsection{Technique}

All this media and material also give one an the optimum chance to explore to his tastes freely in terms of the relationship between man and computer. An interview with Noordin Hassan (1988) summarized Ismail's personal view in dealing with such relation-ship; "It's like dealing with a completely different 
picture surface. A computer is more like a flatbed in a printing press than a stretch canvas, or a piece of paper. That is to say a computer is capable of deliveering from almost infinite source and manipulating a vast heterogeneous array of cultural images and artifacts that had not been compatible with the pictorial field of conventional painting. And it's very fast".

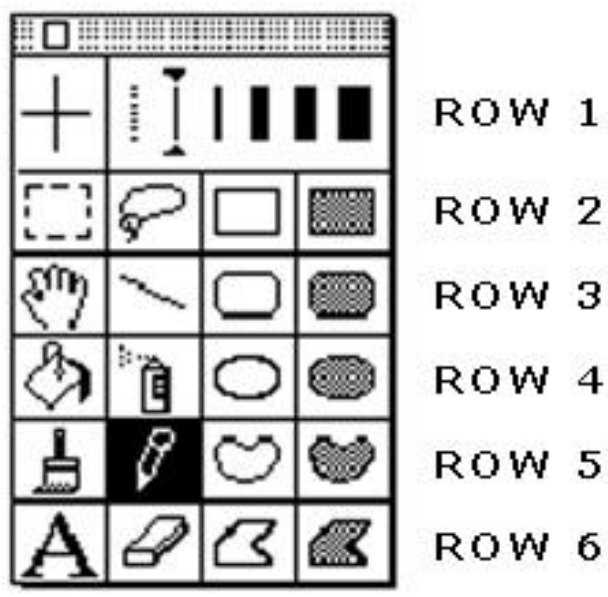

Figure 3 Tool palette from Mac Paint 2.0.

Until at that particular exhibition, images in Ismail's art have been created through act of perception either through skills based in eye/hand coordination. However, the computers capable to read electronically scanned aspects of reality as information about light structure, storing this numerical information in its database which can eventually be programmed to appear as visual imagery. Because of the computer, with its new digital alphabet is capable of encompassing all aspects of information - sound, image, and text within a single data base - a new fusion of discipline is underway. The universality of the computers as a tool for working in the humanities, the science and the arts is creating interesting interdisciplinary effects who promise we are only beginning of fathom. Digital technologies thus become the catalyst for tendencies in the convergence of disciplines, for the universal computer is both a tool and a medium.

Computer had opened Ismail's drive to new possibilities, and approach in making art. The interference of computer technology in art also led to changes in every aspect of fundamental aspects of his art in relation of this chosen medium. In order to use computer as a tool for artistic creation, it also needs software to run before artist can pour their creative ideas. In this context, Ismail's Macintosh computer at that time used software called Mac Paint. In 
Mac Paint, its tools display have been the inspiration for tool palettes for just about all other current drawing, painting, and rendering programs, including Photoshop and Illustrator. If artists can use Mac Paint, they can learn the new drawing software packages with little difficulty (Figure 3).

\subsubsection{Row 1}

Mac Paint 2.0 tool palette is very basic to the con-temporary computer artist. In spite of this, there are certain basics that all artists have to be able to do. One is to draw a line. Along the top row of the palette, one has a series of line thicknesses to choose from. On the image presented, the thinnest of the lines that can be drawn (one pixel wide) is selected for both horizontal and vertical lines. One can move the arrows to different thicknesses for each dimension or even choose the "null" line option (that is the dashed line placed at the left of the selected line thickness).

\subsubsection{Row 2}

Row 2 has some of the most useful tools for Mac Paint. From the left, one has the select rectangle area and the lasso tools. The former allows one to block out a rectangular section of screen and either move that section around or change the characteristics of the area using the commands from the edit menu. Most of the commands from the edit menu only work when a rectangle off area is selected for manipulation. These commands include flipping the selected area horizontally or vertically, rotating the image 90 degrees, and tracing over the lines. The lasso tool allows one to pick out a specific shape on the screen and move it around. Unlike selecting square, you cannot use the edit commands on lassoed shapes. Both select rectangle and lasso allow one to cut and paste images onto other files. To the right of the lasso tool, there is a white rectangle tool and a shaded rectangle tool. These allow one to draw that shape. The white rectangle tool will produce white rectangles according to how you point and click on the mouse. The shaded rectangle tool will produce rectangles with a pattern that is selected from the pattern palette.

\subsubsection{Row 3}

Row 3 has a hand tool to move your view of the 8.5 " by 11 " painting area around. This comes in handy if one has magnified the image resolution to the maximum of $800 \%$. Resolution can be set to as little as $50 \%$ in Mac Paint. To the right is your line drawing tool. This tool allows you to draw straight lines which thickness is based on the selections made back on Row 1. To the right of the line tool are the white and shaded rounded corner rectangle tools. They work like the aforementioned rectangle tools but they leave the corners rounded. These tools are useful for making flowchart boxes and borders. 


\subsubsection{Row 4}

The first two tools on Row 4 are the paint bucket and spray can tools. The paint bucket allows one to fill an enclosed area with a pattern. Caution should be used with this tool. If as much as one pixel in the enclosed area is open, the pattern will escape and fill the page. The spray can tool works like its physical reality counterpart. To the right of the spray can tool, one will find the white oval/circle tool and the shaded oval/circle tool. They work like the aforementioned rectangular tools.

\subsubsection{Row 5}

The first 2 tools on Row 5 are the paint brush and the pencil. The paint brush allows one to draw a pat-tern which shape can be varied by making a section from the Goodies menu that is on the top bar. Shapes vary from a single 4 pixel dots to larger squares and lines. As an added feature, one can activate the brush mirrors feature and create mirror images of paintings. Next to the paint brush is the pencil. It allows one to draw freehand, one pixel lines. It can also erase an image one pixel at a time by putting the pencil tip over a pattern area and clicking on the mouse. The white heart shaped and the shaded heart shaped tools allow for free form, nonlinear drawing. Like the other shaded tools, the heart shaped one will fill in with a pattern after you have released the mouse button.

\subsubsection{Row 6}

The bottom row of the tools palette has the Text Tool, the Eraser Tool, and another pair of shape forming tools. This last set of tools allows one to draw free form polygon shapes. To start a polygon shape, click once on the mouse and draw a line. When the line is done, click on the mouse and start drawing the second line. Repeat the process until the shape is complete then double click to complete the shape. This is how the hour glass shape shown to the left was formed. The text tool does more than just allow one to type words on the page. Using fonts such as Cairo, Mobile, and Symbol, the Mac Paint artist can type in a variety of animals, bullets, vehicles, and other objects in sizes that range from 9 point up to 48 point. The Eraser tool is self-explanatory with one exception. If one presses the apple button, it can erase lines and shapes.

Having mentioned the word pattern so often, an explanation is due. Next to the Tools Palette is the Pat-terns Palette (Figure 4). Like the tools palette, it can be "torn out" and placed anywhere on the screen. The default pattern that the Mac selects is all black. However, one can click on a desired pattern like a background of gray or a pattern of dots. Once the pattern is selected, you can 
install it to a shape using the paint brush, paint bucket, or through drawing shaded rectangles, circles, and other shapes.

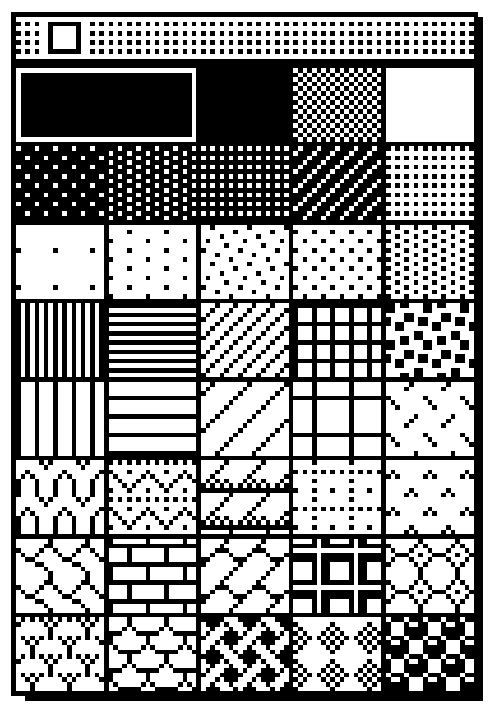

Figure 4 Pattern palette form Mac Paint 2.0.

\subsection{Synthesis}

Overall, Ismail's pieces mostly draw upon culture as the main conception of his work. But, in all of the artworks displayed in the exhibition, it entailed a variety of point of views such as; culture as cross-culture phenomena, culture as multicultural phenomena, culture as popular culture phenomena, culture as global culture and so on. All of his artworks were drawn by his hand through computer using Mac Paint 2.0, and after that they were printed out as black and white digital print on paper, although a few of them were hand colored using gouache after that. His manifestation came in small scale, specifically in standard of international A4 size (approx. $21 \mathrm{~cm}$ x $30 \mathrm{~cm}$ ). Generally, the images that were used in his artworks came from ready-made images that were taken from mass media source which were then juxtaposed according to his intentions of the specific theme.

In Vincent, 1988 (Figure 5), Ismail's shows his inter-st in the challenge of modern aesthetic. This can be translated as an act to challenge old notion from the understanding of space as the material support of time-sharing social practice, to globalization as the planetary extension of such practice made possible by the new information technology. 


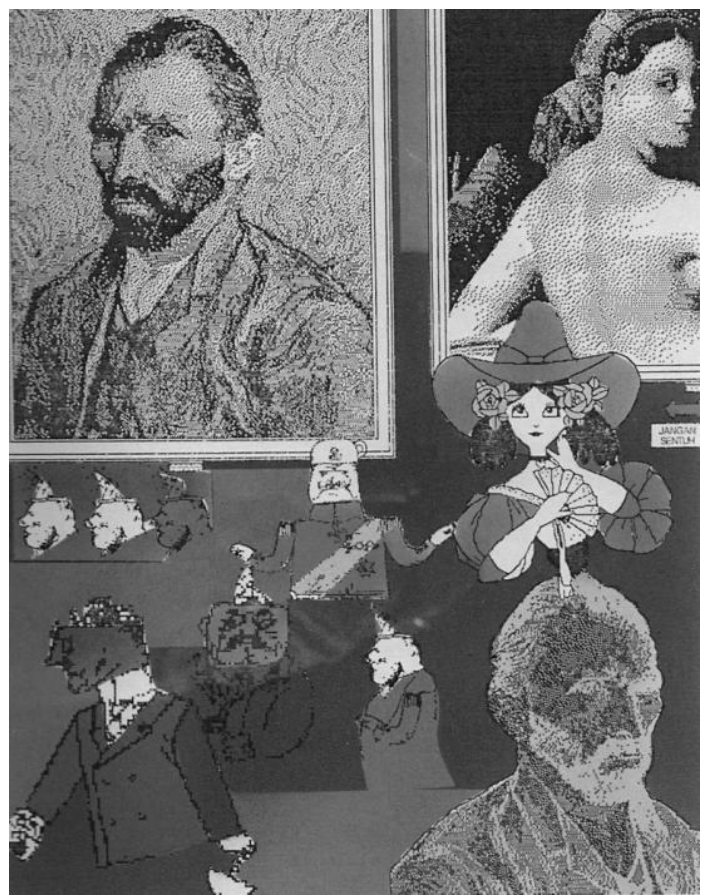

Figure 5 Vincent, 1988, Computer print, $30 \mathrm{~cm}$ x $21 \mathrm{~cm}$.

This black and white digital print generally represented a museum space running an exhibition. In the displays, there were two oil paintings hanging on the wall - a self portrait of Vincent Van Gogh wearing a tight suit and posed to the left and a nude painting by Ingres - a woman posed to the right. In front of the paintings were a couple of men walking in lines with a cone-shaped hats (possibly the ones worn on birthday parties), in which the walking was directed from the arrows which suggested the direction. A caption of reminder was also visible, cautioning the audience not to touch the painting, which was one of museum ethics.

Beside that, there were a couple of men walking into various directions, and a man wearing a royal suit complete with medals. There was also a woman in front of Ingres' nude painting, wearing a cowboy hat, and posed as if it had been drawn as someone outside this area of picture plane. All these human characters, besides the painting, were constructed by Ismail as some sort of cartoon characters. In the be-low bottom of the painting, there was a copy of self portrait of Vincent Van Gogh but, this time, the portrait seems different. The first noticeable criterion of this portrait was that only white dotting and lines over a dark grey surface were used, in contrast to the first portrait of him as a museum exhibit. Besides that, it was only an image without the 
background, gold framing, and of course no trace of identical Van Gogh's strokes of paint.

It is clear that Ismail's intention in challenging aesthetic modernism of consciousness and autonomy because technology allows new spaces whereby process of dematerialized and new translation in the space of flows happen. The new technology does not produce a change in perception and hence in consciousness. The shocks are the result of changes in material reality, which do, therefore, determine forms of attention and modes of perception. The computer begins to assimilate representative itself and principally modern autonomy is being challenged to hold its authority against visual modeling system that is emerging which eclipse their forms. A digitization represents the new world order, the transition to simulacrum which is the copy from the real. Thus, electronic image production is immaterial, existing only as an image structure or an accumulation of data, without physical substance.

So, through these changes, a new type of form emerges and contributes to what Benjamin [11] call loss of aura. This phrase has frequently been interpreted, and commonly aura is associated with the idea of genius, authorship, uniqueness, and originality which are invested in the canonical works of high culture. Meanwhile, it also can be viewed as a promise that of the breakdown of cultural or ultimately social hierarchy. It is a difficult argument, but it seems that aura, for Benjamin, is the sensation of impression of historical experience, produced in the attempt to cushion the abrupt shocks of everyday life.

An aura experience is one which deals with historical discontinuity by replacing it with an illusion of continuity. So, when Benjamin writes of the loss of aura, what is lost is not the real but the false continuum history. It is through the loss of this aura that technology gains a potential to be progressive. One of its aspects that give this potential is the fact that it is experienced collectively in mass rather in chosen smaller group of peoples. The idea of loss of the real assumes that once there was a simple correspondence between representational and reality, a kind of priori authenticity, which has somehow been lost. The concept of lost of aura, however, suggests that what has been lost is this illusion. So, in contemporary dystopian, the old notion of 'distance' which associated with high culture is useless.

The development of electronic media, such as television and telecommunication, brings about an implosion of space and functional organization. Because of the rapid rises of new communication technology, we are now living in a more homogenous and unitary world, a world community shaped in the image of the local village as McLuhan suggests in the 1960s. As a consequence of space travel, we are able to see the world as a completely 
individual entity, as a globe sitting in infinite space. This therefore, is in relation to the shift in our understanding of life itself.

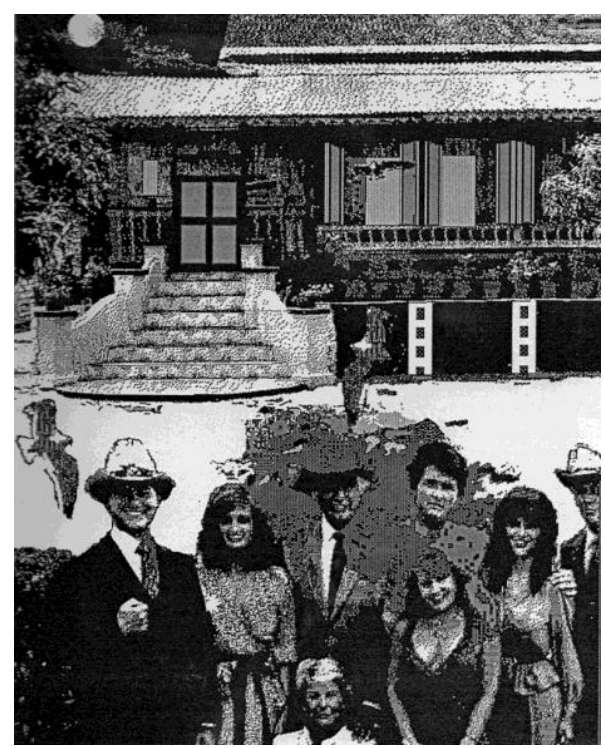

Figure 6 Al-Kesah, 1988, Computer print, $20 \mathrm{~cm} \times 21 \mathrm{~cm}$.

At the bottom of the picture plane was a group of peoples that come from popular culture outside Malaysia. The images can be recognized as Ewing family, taken from most celebrated TV soap opera in the 80s which was carefully drawn from lines and dots from pattern palette, paint bucket, and spray paint bucket that created an illusion of line, shape, texture and form. Generally, it could be recognized that this was some sort of family picture from frontal view as they posed in the soap opera. But, Ismail's cleverly juxtaposed and decontextualized their position from a happy family in Dallas to act as if they were happy tourists who had come to visit Malaysia.

At the middle of the picture plane, there was a map of a country (perhaps America) that was taken from the satellite (a view from the outer space). The positive negative space that were separated by a plain white shape and grays texture were in organic shape that can be described as land and sea. Similarly, it can also be assumed as a front yard of the house, but, logically, it is contrast to the night sky that served as the background of the traditional house. On the top of the map was a couple of birds, probably, the bird had been flying in horizontal position (from left to right) and ended up at the window of the traditional house. It suggests that these birds were in migration from west to east in point of compass. 
As Castells [14] suggests, our contemporary society is constructed around flows; flows of capital flows of information, flows of technology, flows of organization interaction, flows of images, sounds, and symbols. But, not local places are caught up in these processes of globalization because the relationship between space of flows and space of places, between simultaneous globalization and localization are not predetermined by their outcome. Nevertheless, although the places in which people live are not directly caught up in the process of globalization, these people and places are affected by the space of flows.

This is what Ismail wanted to direct his audience to. At the top of the picture plane is a frontal view of a traditional house that rendered precisely including the ornament on the stairs that was identical to Melaka traditional architecture. The dark background of the house suggested night scene with a contrast white circle shape that represented a full moon. As the door of the house was close since it was night time, it was an obvious sign that all the windows of the house were left open, as if to allow the birds to fly in. The integration of all this juxtaposition of images suggested that there was a visit to take place at that house.

Ironically, as far as traditional Malay customs are concerned, visiting hours especially for those who are non-family members is always limited during the day where most Malays think that it is an appropriate time to be at someone's house. To counter that as a borderless time-space relationship within two cultures, Ismail carefully added other images such as a full moon in the dark night sky and a couple of mi-grant birds that fly across the map of the world. Such combination of images was clearly a brilliant association which tells us how these meetings were held, and how traditions perspective were started to get deconstructed by the power of technology. To view this in context of late 80s environment in Malaysia, most families were spending their night time after a long labor during the day with watching television. Television at that time was not an elitist object anymore since the peoples outside urban areas also could afford it.

This is what Castells [14] was writing about time-less time, such a time can be constructed and reconstructed and around space of flows. In timeless time, all the interaction might be geared around the time of other global trading partners rather than any notion of day-time, night-time, and sleep-time, and so on within one time zone and around space of flows. Timeless time is a consequence of the material transformation that are typified by his notion of the network society, which how local practices are increasingly connected to global process; global is not a place, but a process where peoples around the world are simultaneously enjoying and downplaying at the same time. 
So, when the house was pictured as close door, we easily can understand that the visits is not physically presence, but from transmitted presence which by means altered the limitation of place relationship in the idea of locale, which refers to radical transformation of social order from traditional village which all activity must be held in physical settings geographically and face-to-face interaction to what Giddens [10] called space relationship where modern condition permits any social activity to be conducted at a distance. Consequently, this divorcement of place-to-space makes place becomes 'phantasmagonic', that is to say, any geographical areas can be shaped in terms of any influence that come quite distant from them. In this context, a couple of migrant birds which flew freely across the map of the world suggested this notion clearly enough.

\section{$5 \quad$ Conclusions}

This study started from the researcher's literature re-view about Malaysian contemporary art. Having glimpses at books and catalogue essays, the researcher discovers that there is a loop in over viewing Malaysian contemporary art. Although the myth making writes something about how it arrived in Malaysia, but, nothing much has been said especially about Ismail Zain, one of the pioneers in new media art. Maybe because of his demise in the early years of 1990s, and that had become a very big obstacle for researchers to dig up what was going on in his art and his thoughts.

From the researcher's experience in this study, it helps to understand that art can be studied in terms of its process. This approach is also helpful in understanding the relationship between the artist and the work at the same time. The artist leads the researcher to comprehend what was going on in his mind and how he used his material and technique in order to create the artwork, and the artwork lets the researcher to understand how such ideas and media are transformed into visual image.

This research has led the researcher to conclude that art in general, and art making in specific cannot be situated in a close-system. To put art in such condition, it helps to give a holistic understanding about art from many aspects that are related even though there are risks and consequences. From this fundamental understanding, if art want to be a body of knowledge, it has to be prepared to be investigated and scrutinized from multiple points of view.

\section{Acknowledgement}

I gratefully acknowledge Ass. Prof. Dr Najib Dawa, Mr. Osmihamidy Osman and Mr. Tan Sei Hon from Balai Seni Lukis Negara Malaysia for providing the 
data and assistance in Malaysia. I also thanks to Prof. Dr. Setiawan Sabana and Prof. Dr Tjetjep Rohendi Rohidi for their advise and encouragement towards completing this study.

\section{References}

[1] Piyadasa, R. 1993. Modern Malaysian art 1945-1991: a historical overview, in Turner, C (ed). Tradition and Change: Contemporary Art of Asia and the Pacific. Queensland. University of Queensland Press.

[2] Antoinette, M. 2002. Different visions: contemporary Malaysian art and exhibition in the 1990s and beyond, in Turner, C (ed). Art and Social Change. Canberra. Pandanus.

[3] Read, H. 1944. Education through Art, London. Faber \& Faber.

[4] Barrett, M. 1982. Art Education: A Strategy for Course Design, London, Heinemann Education Books.

[5] Weitz, M. 2007. The role of theory in aesthetics, in Wartenberg, T. The Nature of Art: An Anthology. California. Thomson Wadsworth.

[6] Prinz, J. 1991. Art Discourse/Discourse in Art, New Jersey, Rutgers University Press.

[7] Owens, C. 1984. The allegorical impulse towards a theory of Postmodernism, in Wallis, B (ed). Art After Modernism: Rethinking Representation. New York. The New Museum Of Contemporary Art.

[8] Joselit, D. 2003. American Art Since 1945, London, Thames \& Hudson Ltd.

[9] Jit, K. 1999. Ismail Zain: Retrospective Exhibition 1964-1991, Kuala Lumpur. National Art Gallery.

[10] Giddens, A. 1990. The Consequences of Modernity, Cambridge Polity Press.

[11] Benjamin, W. 1968. Illuminations, New York, Schocken Book.

[12] Appadurai, A. 1990. Disjuncture and difference in the global cultural economy, in Featherstone, M (ed). Global Culture: Nationalism, Globalization and Modernity. London. Sage.

[13] Saidon, H.J. \& Rajah, N. Pameran Seni Elektronik Pertama. Kuala Lumpur. Balai Seni Lukis Negara.

[14] Castells, M. 1996. The Rise of the Network Society. Oxford. Blackwell. 